\title{
Indolizy Carbene Ligand. Evaluation of Electronic Properties and Applications in Asymmetric Gold(I) Catalysis
}

\author{
Thibaut Martinez, ${ }^{[\mathrm{a}]}$ Avassaya Vanitcha,${ }^{[\mathrm{a}]}$ Claire Troufflard, ${ }^{[\mathrm{a}]}$ Nicolas Vanthuyne, ${ }^{[\mathrm{b}]}$ Jérémy Forté,${ }^{[\mathrm{a}]}$ \\ Geoffrey Gontard, ${ }^{[\mathrm{a}]}$ Gilles Lemière, ${ }^{[\mathrm{a}] *}$ Virginie Mouriès-Mansuy ${ }^{[\mathrm{a}]_{\star}}$ and Louis Fensterbank ${ }^{[\mathrm{a}] *}$
}
[a] Dr. T. Martinez, Dr. A. Vanitcha, C. Troufflard, J. Forté, G. Gontard, Dr. G. Lemière, Dr. V. Mouriès-Mansuy, Prof. L. Fensterbank Institut Parisien de Chimie Moléculaire
Sorbonne Université, CNRS
4 Place Jussieu, CC 229, F-75252 Paris Cedex 05 (France)
E-mail: gilles.lemiere@sorbonne-universite.fr, virginie-mansuy@sorbonne-universite.fr, louis.fensterbank@sorbonne-universite.fr
[b] Dr. N. Vanthuyne
Aix Marseille Univ, CNRS, Centrale Marseille, iSm2
F-13397 Marseille Cedex 20 (France)
Supporting information for this article is given via a link at the end of the document.((Please delete this text if not appropriate))

\begin{abstract}
We report herein a new family of carbene ligands based on an indolizine-ylidene (Indolizy) moiety. The corresponding gold(I) complexes are easily obtained from the gold(I)-promoted cyclization of allenylpyridine precursors. Evaluation of the electronic properties by experimental methods and also by DFT calculations confirm strong $\sigma$-donating and $\pi$-accepting properties of these ligands. Cationization of the gold(I) complexes generates catalytic species that trigger diverse reactions of (poly)unsaturated precursors. When armed with a methylene phosphine oxide moiety on the stereogenic center adjacent to the nitrogen atom, the corresponding bifunctional carbene ligands give rise to highly enantioselective heterocyclizations. DFT calculations brought some rationalization and highlighted the critical roles played by the phosphine oxide group and the tosylate anion in the asymmetric cyclization of $\gamma$ allenols.
\end{abstract}

\section{Introduction}

The last decades have witnessed a strong expansion in homogeneous gold catalysis promoting a broad range of organic transformations. ${ }^{[1]}$ The high $\pi$-Lewis acidity of cationic gold(I) complexes allow them to activate various unsaturations such as alkynes, allenes and also alkenes towards intra- or intermolecular nucleophilic addition. ${ }^{[2]}$ During the process, the ligands carried by the gold(I) center play a major role in terms of stability, allowing low catalyst loadings, modulation of activity, and selectivity. ${ }^{[3]}$ Furthermore, the linear coordination of gold(I) complexes that positions the ancillary ligand opposite to the substrate and thus to the outer-sphere attack of the nucleophile renders asymmetric gold catalysis a challenging goal. ${ }^{[4]}$ The role of the chiral ligand is therefore crucial notably by constraining the degrees of freedom of the system. In this context, $C$-ligands such as $\mathrm{N}$-heterocyclic carbenes (NHCs $\mathbf{A})^{[5]}$ have exhibited high potential. More accessible than a lot of phosphine ligands that are tedious to prepare and prone to oxidation, they have the ability to form stable complexes thanks to strong $\sigma$-bonding with the gold metallic center while $\pi$-backbonding to the carbene will be highly dependent from its structural features, the interplay of both effects leading to specific reactivities. ${ }^{[6]}$ In 2005 , the group of Bertrand ${ }^{[7]}$ developed a new class of carbenes, the cyclic (alkyl)(amino)carbenes (CAACs B) in which a nitrogen of a classical NHC diaminocarbene was replaced by a carbon atom. Those are more $\sigma$-donating and $\pi$-accepting than the parent NHCs. ${ }^{[8]}$ The corresponding gold complexes ${ }^{[9]}$ have led to the first examples of hydroamination of alkynes and allenes using ammonia or hydrazine. ${ }^{[10]}$ The replacement of the alkyl substituent of CAACs by an aryl leads to the formation of new cyclic (amino)(aryl)carbenes (CAArCs C), ${ }^{[11]}$ that still feature high nucleophilicity but also enhanced electrophilicity resulting in a smaller single-triplet gap than for CAACs.

The implementation of asymmetric gold-catalyzed processes relying on monodentate $C$-ligands has initially consisted in the introduction of stereogenic centers on the imidazolium backbone or on the $\mathrm{N}$-ligated substituents. ${ }^{[12,13]}$ Tomioka and coll. ${ }^{[14]}$ synthesized the first chiral $C_{2}$-symmetric dihydroimidazol-2ylidene gold(I) complexes and applied them in a moderately enantioselective methoxycyclization of 1,6-enynes (up to $59 \%$ ee). Improved enantioselectivities (above 70\%) for similar reactions were observed using $\mathrm{C}_{2}$-symmetric $\mathrm{NHC}$ complexes bearing bulky stereogenic $N$-substituents. ${ }^{[15,16]}$ Still, these systems suffer from the fact that the nitrogen substituents are too remote from the gold center to fix an adequate steric environment and several strategies for the introduction of higher performance elements of chiral discrimination have been proposed to render carbenes the ligands of choice for asymmetric gold-catalyzed transformations. ${ }^{[17]}$ Notably, NHCtype ligands based on an imidazo[1,5-a]pyridine-3-ylidene (ImPy D) skeleton, initially disclosed by the groups of Lassaletta ${ }^{[18]}$ and Glorius ${ }^{[19]}$ have allowed the synthesis of new families of carbene ligands by the introduction of substituents at the C5 position. The latter are in close proximity to the metal-center and can be designed to convey properties to the gold complexes. ${ }^{[20]}$ For instance, the $\pi$-acceptor properties of ImPy ligands were enhanced by the introduction of a cyclophane scaffold and found applications in the catalysis of the cycloisomerization of eneallenes. ${ }^{[21]}$ The substitution at the $\mathrm{C} 5$ position constitutes also an opportunity to provide axially chiral complexes. ${ }^{[22]} Z$ hang further refined this approach by providing chiral bifunctional $\mathrm{NHC}$ ligands flanked with a tetrahydroisoquinoline moiety at the $\mathrm{C} 5$ position. ${ }^{[23]}$ The corresponding gold complexes proved to be competent in a series of asymmetric transformations (Figure 1). 
Regarding CAACs, the presence of a quaternary carbon center adjacent to the ylidene carbon is a good lever to introduce stereogenicity close to the active site. Bertrand and coll. initially prepared an enantiopure (-)-menthol derived CAAC ligand $^{[7 a]}$ but no asymmetric catalysis in a copper-catalyzed asymmetric conjugated borylation reaction was recorded, ${ }^{[24]}$ this being certainly due to a conformational inversion of the menthyl group. In contrast, a more rigid CAAC with extended chirality derived from a $5 \alpha$-cholestan-3-one steroid backbone was recently synthesized and the corresponding copper complex ${ }^{\text {Cholest }} \mathrm{CAACCuCl}$, promoted encouraging enantioselectivity $(55 \%$ ee) in the same borylation reaction. ${ }^{[2,25]}$ It should also be noted that racemic chiral CAACAuCl complexes have been prepared by Kumar and Waldmann via a $\mathrm{Me}_{2} \mathrm{SAuCl}$-promoted cyclizationrearrangement sequence of 1,7-enynes and two examples of catalysis were given. ${ }^{[26]}$

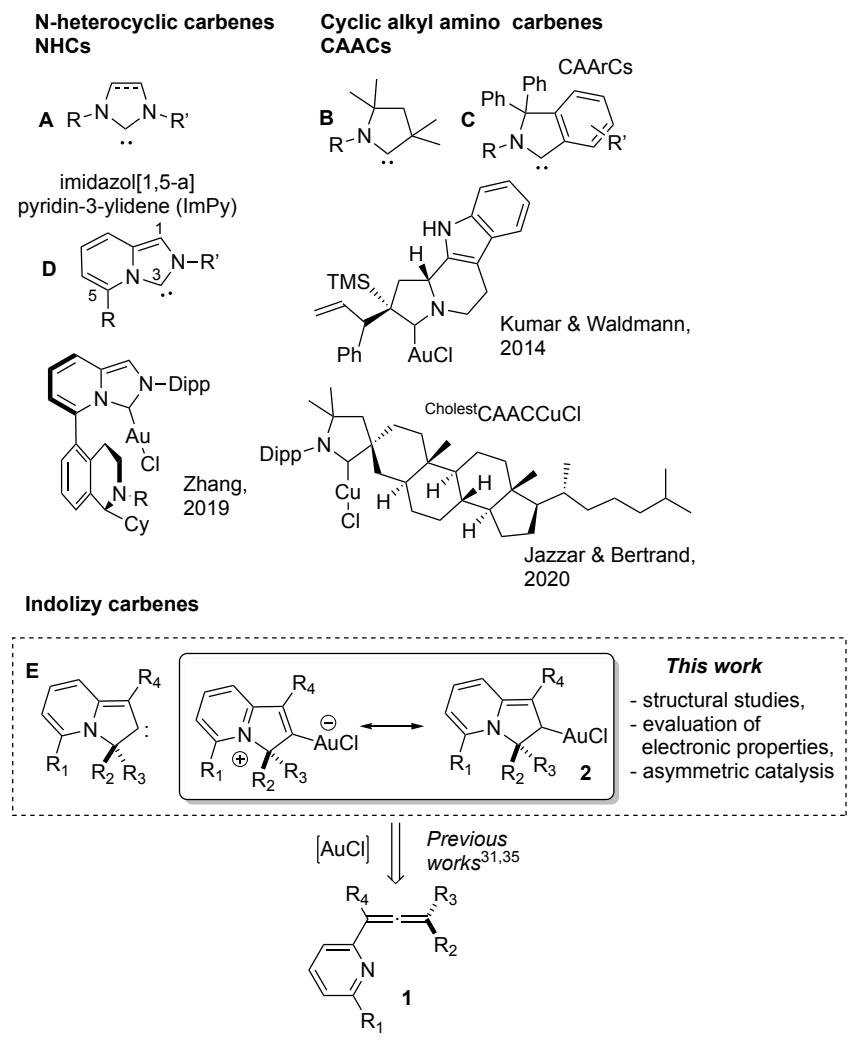

Figure 1. Milestones in the development of $\mathrm{Au}(\mathrm{I})$-carbene complexes and presentation of the work

As part of our ongoing interest in the design of new chiral ligands for gold complexes ${ }^{[27-29]}$ we have devised the new family of Indolizy $C$-ligands $\mathbf{E}$, possibly bifunctional ${ }^{[30]}$ (Figure 1). While direct isolation of these ligands has not been accomplished so far, we found more convenient to directly access to the corresponding gold complexes 2 through an efficient goldpromoted cyclization of allenepyridines of type 1 that we previously worked out. ${ }^{[31,32]}$ Two resonance forms can be written for complexes of type 2, vinylgold vs carbene, but the very short Au-C bond distance (1.993(4) $\AA$ ) on $\mathbf{2 a},{ }^{[33]}$ reminiscent of other gold carbenes, ${ }^{[34]}$ suggested a carbenic character favorable for catalytic applications. Overall, the ligands E connected to the gold center of complexes 2 could be considered as the first examples of vinylogous $\mathrm{CAACs}^{[7]}$ that also include chiral congeners.

Prompted by a recent report from the Muñoz group on a related use of bis-pyridyl allenes $1\left(R_{1}=M e, R_{2}=2-\right.$ methylpyridine) as precursors of gold carbenes and their preliminary catalytic activity, ${ }^{[35]}$ we herein extend the family of gold(I) complexes 2, evaluate the electronic properties conferred by ligands $\mathbf{E}$ and study their catalytic applications notably in enantioselective gold $(I)$ catalysis.

\section{Results and Discussion}

Preparation of a family of gold(I) complexes 2 . We synthesized a wide range of gold $(I)$ complexes 2 including achiral complex 2b and chiral complexes $\mathbf{2 a}$ and $\mathbf{2 c}-\mathbf{k}$. As depicted in Scheme 1, they were obtained in two steps from propargyl acetates 3 and $\mathbf{3}^{\prime}$. $\mathrm{S}_{\mathrm{N}} 2$ ' reactions on the latter provided various pyridyl-allenes 1 that were engaged in the previously mentioned cyclization reaction using 1 equiv. of $\mathrm{Me}_{2} \mathrm{SAuCl}$ to smoothly deliver complexes $2 .^{[31]}$ Through this route, we could control strategic positions on chiral complexes $( \pm)-2$ : i) the nature of the stereogenic center, either devoid of an additional coordinating group (2c) or flanked with a $\beta$-phosphorus group (phosphine oxide for $\mathbf{2 a}$ and $\mathbf{2} \mathbf{d}-\mathbf{g}$ featuring an increasing steric demand, phosphine sulfide for $\mathbf{2 h}$ and phosphonate for $\mathbf{2} \mathbf{i}$ ), ii) the vinyl position close to the gold(I) center by varying the aryl scaffold through the introduction of a 4,6-dimethylphenyl moiety (complexes 2d and 2f). The obtained cyclization yields for complexes 2, from quantitative for $\mathbf{2 a - c}$ to $34 \%$ for $\mathbf{2 f}$ were relatively consistent with the steric bulk imposed by the substituents of the allene moieties and gave sufficient material for catalytic trials. X-ray diffraction (XRD) analyses were obtained for complexes $2 \mathbf{c}-\mathbf{2 f} .^{[33]}$ The $\mathrm{Au}-\mathrm{C}$ bond lengths lie in the same range from 1.990(6) $\AA$ for $\mathbf{2 d}$ to 2.002(1) $\AA$ for $\mathbf{2 f}$. As shown also on Scheme 1, for complexes 2 bearing a phosphine oxide, a stabilising dipole-dipole interaction between the oxygen of the phosphine oxide and the nitrogen atom of the $\mathrm{N}$ containing 6-membered ring seems to operate with an average O-N distance of $2.95 \AA$.

To obtain enantiomerically pure complexes $\mathbf{2}$, we relied on a total chirality transfer in the gold-promoted cyclization. ${ }^{[1]}$ This could be accomplished from allene (-)-1a to give precatalyst catalyst (-)-(S)-2a whose absolute configuration was determined by XRD.$^{[36]}$ Nevertheless, we found more convenient to obtain each enantiomer of complexes $\mathbf{2 a}$ and $\mathbf{2 c}-\mathbf{i}$ by preparative chiral HPLC. ${ }^{[37]}$ It should be noted that thiophosphine complex $\mathbf{2 h}$ could not be resolved and proved unstable in the HPLC conditions. We were also able to directly obtain enantiopure indolizy-gold(I) complexes $\mathbf{2} \mathbf{j}$ and $\mathbf{2 k}$ using inexpensive (-)menthone from the chiral pool. ${ }^{[7]}$ In three steps including initially the addition of ethynylmagnesium bromide onto (-)-menthone, ${ }^{[38]}$ a mixture of two separable diastereoisomeric propargylic acetates $\mathbf{3 j}$ and $\mathbf{3 k}$ was obtained. Subsequent cuprate addition led to the formation of tetrasubstituted allenes as single diastereomers in an excellent yield of $97 \%$ for both (aS)-1 $\mathbf{j}$ and $(a R)-1 \mathbf{k}$. Finally, the corresponding chiral gold(I) complexes $\mathbf{2 j}$ and $2 \mathbf{k}$ were obtained in respectively $52 \%$ and $99 \%$ yield, by stereospecific reaction with $\mathrm{Me}_{2} \mathrm{SAuCl}$. The structure of $\mathbf{2 k}$ was confirmed by XRD analysis (see $\mathrm{SI}) .{ }^{[39]}$ 


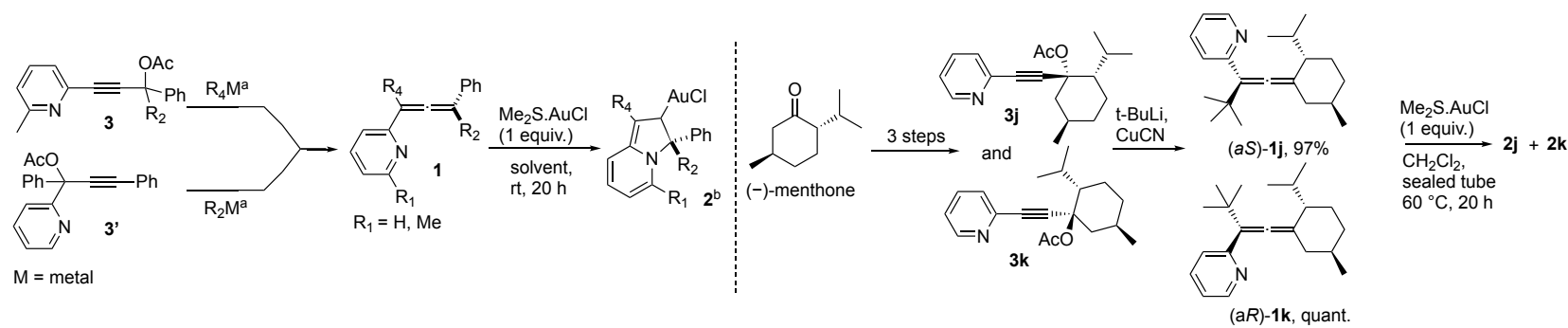

(1)

2a, quant. ${ }^{b}$
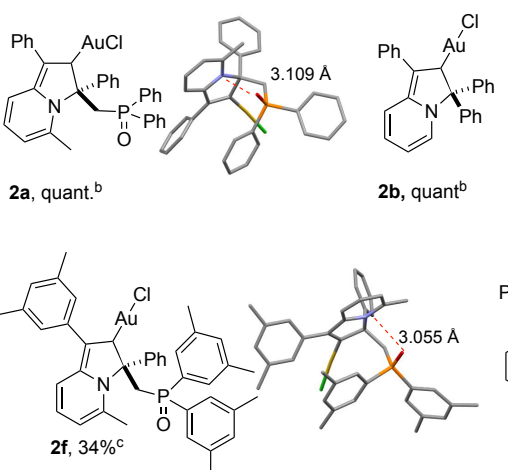

2b, quant ${ }^{b}$
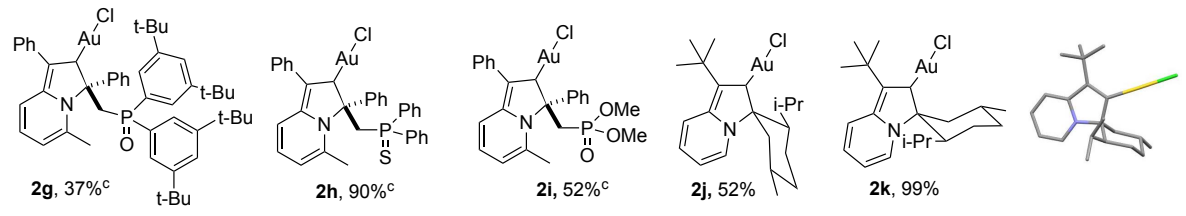

a See SI for details; ${ }^{b}$ solvent: $\mathrm{CH}_{2} \mathrm{Cl}_{2}$; ${ }^{\text {csolvent: DCE }}$

Scheme 1. Indolizy Au(I) precatalysts 2

Evaluation of the Electronic properties. The modification of the $\mathrm{NHC}$ backbones can dramatically change their electronic features. ${ }^{[40]}$ Based on this fact, we have first determined the geometries and energies of the frontier orbitals for the free ligand Indolizy-b of complex $\mathbf{2 b}$ (see also Figure 2) by means of
DFT calculations at the B3LYP/def2-TZVP level of theory. It was found that the HOMO of Indolizy-b $(-4.97 \mathrm{eV})$ lies considerably higher than those calculated for relevant CAACs considered as very good $\sigma$-donor ligands. This data highlights the tendency of the ylidene carbon to increase its electron-donating ability when decreasing the number of electronegative nitrogen atoms connected to it. ${ }^{[41]}$
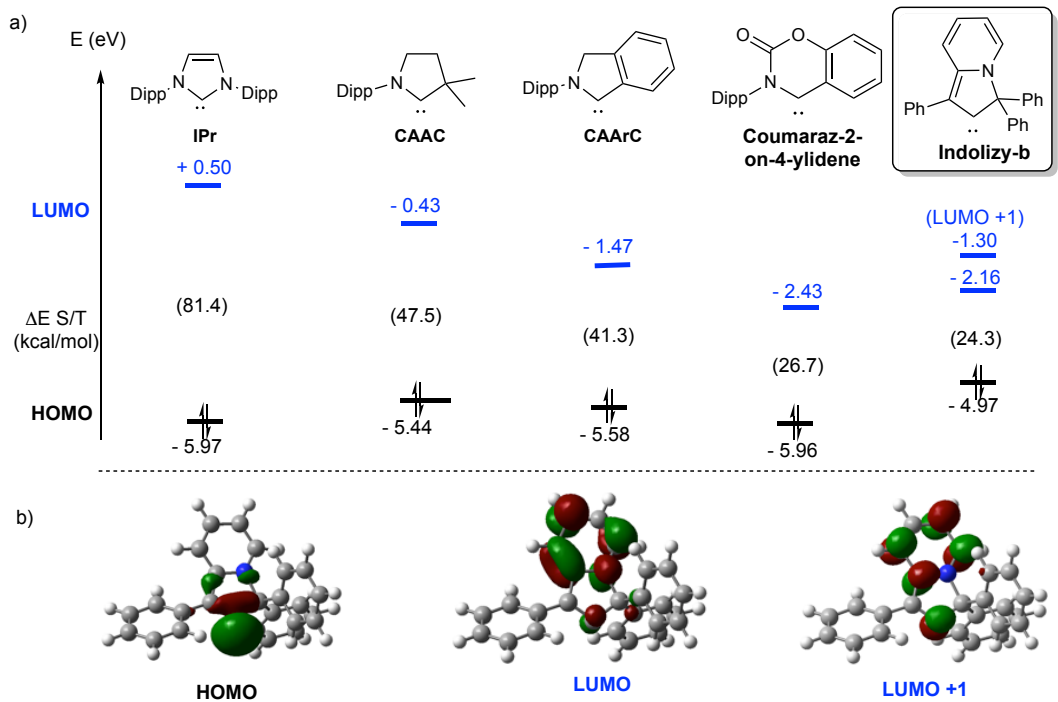

Figure 2. a) Relevant HOMOs and LUMOs (present on the ylidene carbon) energy levels and singlet-triplet transition energy of a series of relevant NHC including Indolizy-b calculated at the B3LYP/def2-TZVP level of theory b) Vizualisation of the frontier orbitals of Indolizy-b plotted with Gaussview at an isosurface value of 0.05 au 
Intriguingly, Indolizy-b exhibits a LUMO lying at a very low energy level that is at first glance suggestive of an exceptional $\pi$ acidity for this ligand, comparable to the coumaraz-2-one-4ylidene carbene. ${ }^{[42]}$ Nevertheless, $\pi$-acceptor capabilities correlate with the energies of the relevant $\pi^{*}$-orbitals and not necessarily the LUMO so that the sole consideration of the LUMO energy can be misleading. ${ }^{[43]}$ Visualization of the shape of the frontier orbitals allows for a qualitative estimation of their geometrical appropriateness for a possible overlap with the metals d-orbitals. While the HOMO of Indolizy-b is mainly located on the ylidene carbon, the LUMO is rather opposite to this site and mainly delocalized over the $\mathrm{N}$-containing 6membered ring (Figure 2b). Interestingly, the LUMO+1 that lies slightly higher than the one calculated for a highly $\pi$-acidic $\operatorname{CAArC}^{[11]}(-1.30$ vs -1.47$)$, is much present on the ylidene carbon and therefore can also account for the overall $\pi$-acidity of the ligand. Finally, Indolizy-b presents a very small singlet-triplet gap $(24.3 \mathrm{kcal} / \mathrm{mol})$ smaller than the one calculated for the coumaraz-2-one-4-ylidene carbene $(26.7 \mathrm{kcal} / \mathrm{mol})$, which presages good bonding abilities. ${ }^{[4]}$

To experimentally corroborate these calculations, we first gauged the donating ability of the Indolizy ligand following the Huynh Electronic Parameter (HEP). This method, initially based on the ${ }^{13} \mathrm{C}$ NMR spectroscopy analysis of trans- $\left[\mathrm{PdBr}_{2}\left(\mathrm{PPr}_{2}\right.\right.$ bimy)L] (iPr2-bimy = 1,3-diisopropylbenzimidazolin-2-ylidene) complexes on which $\mathrm{L}$ is a NHC ligand, has also been transposed to $\left[\mathrm{Au}\left(\mathrm{PPr}_{2}\right.\right.$-bimy $\left.) \mathrm{L}\right]$ gold $(\mathrm{I})$ complexes. ${ }^{[45,46]}$ While the HEP method has never been used for the evaluation of the $\sigma$ donation of CAACs or analogues, we nevertheless synthesized the $\left[\mathrm{Au}\left(\mathrm{PPr}_{2}\right.\right.$-bimy)(Indolizy-b)]BF 4 complex $\mathbf{5}$ in good yield $(84 \%)$ through a one-pot reaction by mixing ${ } \mathrm{Pr}_{2}$-bimyH ${ }^{+} \mathrm{BF}_{4}^{-}$(4) in the presence of $\mathrm{K}_{2} \mathrm{CO}_{3}$ and gold complex $\mathbf{2 b}$ (Scheme 2). The structure of 5 was secured by XRD analysis. ${ }^{[47]}$ As expected, a linear coordination pattern in which the central gold $(I)$ atom is both coordinated to the $i \mathrm{Pr}_{2}$-bimy and Indolizy-b ligands was observed. The isopropyl $\mathrm{C}-\mathrm{H}$ protons of complex $\mathbf{5}$ appeared by ${ }^{1} \mathrm{H}$ NMR as a multiplet at $5.05 \mathrm{ppm}$, falling in the range of the expected values for this type of complexes, and which indicated a free rotation around the Au- $\mathrm{C}_{\text {carbene }}$ bonds. ${ }^{[45]}$ Moreover, the ${ }^{13} \mathrm{C}$ NMR spectrum of $\mathbf{5}$ exhibited two carbene resonances at 193.1 ppm, presumably for the $i \mathrm{Pr}_{2}$-bimy carbene and more downfield at $204.5 \mathrm{ppm}$ for the Indolizy ligand. A two dimensional HMBC NMR analysis confirmed these assignments (see $\mathrm{SI}$ ). Based on the linear correlation between the ${ }^{13} \mathrm{C}_{\text {carbene }}\left(\mathrm{Pr}_{2}\right.$-bimy) values for the $\mathrm{Pd}(\mathrm{II})$ and $\mathrm{Au}(\mathrm{I})$ complexes, a HEP value of $184.7 \mathrm{ppm}$, corresponding to the highest HEP value ever found for a carbene ligand, and much higher than the HEP of $\operatorname{IPr}(177.5$ $\mathrm{ppm}$ ), was determined for the Indolizy ligand. It therefore appears that Indolizy ligand features strong $\sigma$-donating properties which fits with the DFT calculations.

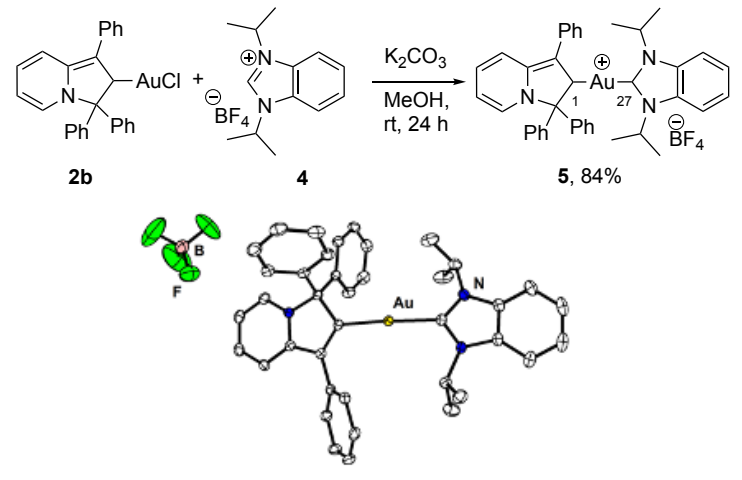

Scheme 2. Synthesis of complex $\mathbf{5}$ and its $X R D$ structure (hydrogen atoms are omitted for clarity). Selected bond lengths $(\AA)$ and angle (deg): Au1-C27 2.035(3), Au1-C1 2.033(3), C1-Au1-C27 174.5(1) ${ }^{\circ}$

Next, the $\pi$-acceptor character of the Indolizy ligand was assessed by measuring the ${ }^{77}$ Se NMR chemical shift of the selenium derivative $6{ }^{[48-49]}$ prepared in $85 \%$ yield by mixing in acetonitrile elemental selenium with allene $1 \mathrm{~b}$ at $130^{\circ} \mathrm{C}$ in a sealed tube for $22 \mathrm{~h}$ (Scheme 3$)^{[50]}$ The structure was ascertained by a single crystal XRD analysis. ${ }^{[1]}$

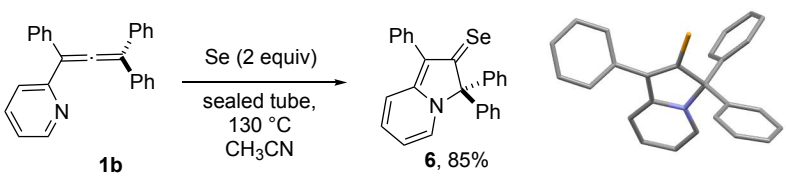

Scheme 3. Synthesis of Indolizy selenide derivative 6

With a $\delta{ }^{77}$ Se NMR value of $566.7 \mathrm{ppm}$ in acetone- $d_{6}$ and $528.1 \mathrm{ppm}$ in $\mathrm{CDCl}_{3}$, Indolizy ligand appears far more $\pi$ accepting than $\operatorname{IPr}\left(\delta{ }^{77} \mathrm{Se}: 87.0 \mathrm{ppm} \text { in acetone- } d_{6}\right)^{[48]}$ but slightly less $\pi$-accepting than the CAArC of Figure $2\left(\delta{ }^{77} \mathrm{Se}: 601\right.$ $\mathrm{ppm}) .{ }^{[11]}$ Interestingly this last finding is also consistent with the above-presented DFT study.

We also examined the impact of the electronic properties of the Indolizy ligand by using the gold(I) precatalyst $2 \mathbf{a}$ in a diagnostic reaction consisting in the cycloisomerization of allenediene 7 (Scheme 4). It was shown that in this transformation the $\pi$-activation of the allene by a cationic gold $(\mathrm{I})$ catalyst triggers the generation of a cationic intermediate $\mathbf{8}$. The latter can evolve following two pathways depending on the influence of the ancillary ligand: an alkyl shift or a 1,2-hydride shift giving respectively the [4+2] cycloadduct 9 or the [4+3] cycloadduct $10{ }^{[52]}$ Bicyclic product 10 is a marker of a strong donor ligand which favors a carbene reactivity of intermediate $\mathbf{8}$. For instance $\mathrm{IPr}$ or IMes ligand will provide almost exclusively $10^{\left[{ }^{[52]}\right.}$ In contrast, hydrindane product 9 suggests a cationic pathway because of the reduced donation of the ancillary ligand. This is what happens when using $\pi$-accepting cyclophane-NHCs which yields a $72: 28$ ratio of 9 vs. $10 .{ }^{[21]}$ In the presence of $\mathrm{AgSbF}_{6}$ and 2a, a 74:26 mixture of cycloadducts 9 and 10 was obtained in $67 \%$ yield. While this type of ratio has to be taken cautiously since steric effects can also be at play, ${ }^{[52 e]}$ the convergence between the ${ }^{77} \mathrm{Se}$ NMR value and this experiment suggests significant $\pi$-acidic properties of the Indolizy ligand. 


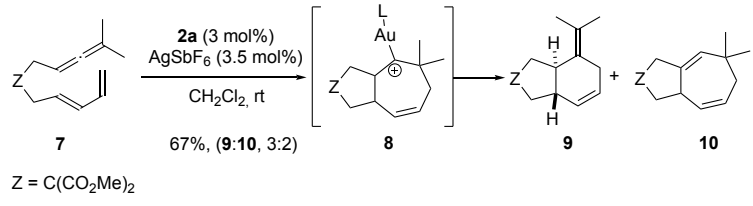

Scheme 4. Diagnostic reaction using the allenediene precursor 7

Applications in asymmetric catalysis. Besides the cyloisomerization of $\mathbf{7}$, we checked the reactivity of precatalyst 2a in a few diagnostic reactions (see $\mathrm{SI}$ ). Consistent results with literature were obtained. We also checked the configurational stability of $(-)-(S)-2 d$ in thermal conditions $\left(80^{\circ} \mathrm{C}\right.$ for $24 \mathrm{~h}$, see $\mathrm{SI})$. All these positive data drove us to test asymmetric catalysis with Indolizy-Au complexes 2 (except $\mathbf{2 h})^{[53]}$ We first studied the methoxycyclization of enyne $\mathbf{1 1}$ that has served as benchmark reaction in numerous studies. ${ }^{[2]}$ Using typical conditions $\left(\mathrm{AgSbF}_{6}\right.$ as cationizing agent in $\mathrm{MeOH}$ at $\mathrm{rt}$ ), low enantioselectivities were recorded, the best resulted of $28 \%$ ee being obtained with complex $(+)-(S)-2 f$ (Table 1 , entry 5$)$. Interestingly, a precatalyst bearing a gem-dialkyl group ((+)-2c) with no additional functionality provided a racemic mixture (entry 2) while the other complexes bearing a phosphine oxide substituted arm allowed some tangible enantiomeric discrimination.

Table 1. Methoxycyclization reaction

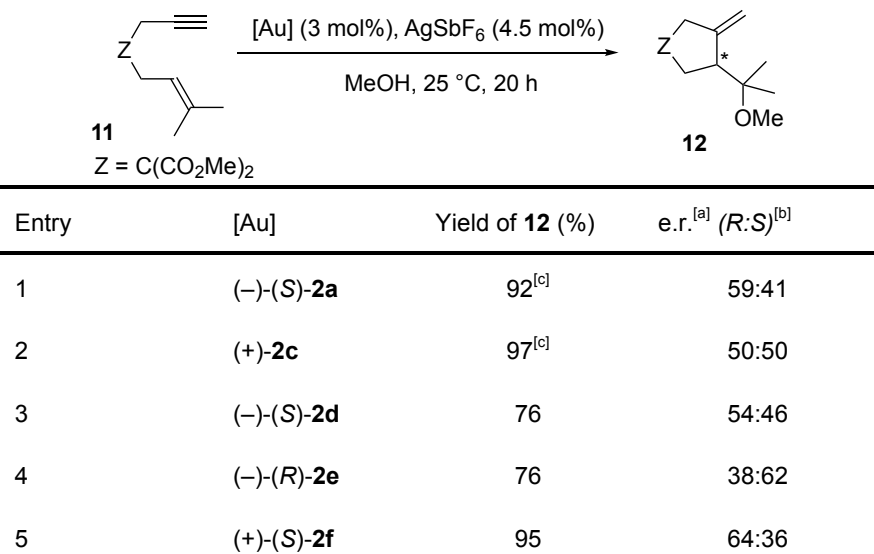

[a] Enantiomeric ratios were determined by chiral HPLC; [b] The configurations were assigned by comparison with literature. ${ }^{[29] ;}$ [c] NMR yields with trimethoxybenzene as internal standard.

Based on these promising findings, we examined the purely intramolecular gold-catalyzed hydroalkoxylation of 4,5hexadiene-1-ols $\mathbf{1 3 a}$ and $\mathbf{1 3 b}$ and the results are summarized in Table 2. Precatalysts 2 were first activated with a silver salt before the addition of substrates 13 . We started our studies with gold(I) complex (-)-(S)-2a and initially checked the influence of the silver salt as cationizing agent on the enantioselectivity of the reaction. At $25^{\circ} \mathrm{C}$ with $\mathrm{AgSbF}_{6}$ in toluene (entry 1 ), low yield of $14 a(16 \%)$ was obtained with almost no enantioselectivity (e.r. $=45: 55$ ). Increasing the temperature to $50^{\circ} \mathrm{C}$ (entry 2 ) resulted in a yield increase $(52 \%)$ but a decrease of enantioselectivity.
Keeping this temperature with other silver salts (entries 3-4), low yields of $14 a$ in racemic form were observed.

Table 2. Intramolecular hydroalkoxylation.

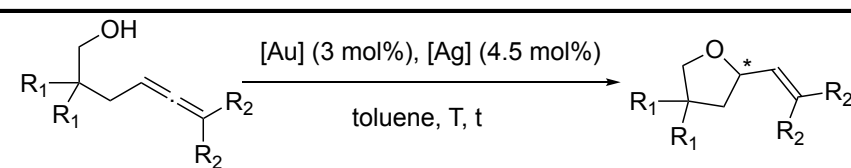

13a, $R_{1}=P h, R_{2}=H$
$13 b, R_{1}=H, R_{2}=-C_{5} H$

14a, $\mathrm{R}_{1}=\mathrm{Ph}, \mathrm{R}_{2}=\mathrm{H}$

\begin{tabular}{|c|c|c|c|c|c|c|}
\hline \multicolumn{5}{|c|}{$13 b, R_{1}=H, R_{2}=-C_{5} H_{10^{-}}$} & \multicolumn{2}{|c|}{$14 \mathrm{~b}, \mathrm{R}_{1}=\mathrm{H}, \mathrm{R}_{2}=-\mathrm{C}_{5} \mathrm{H}_{10^{-}}$} \\
\hline Entry & {$[\mathrm{Au}]$} & {$[\mathrm{Ag}]$} & $\mathrm{T}\left({ }^{\circ} \mathrm{C}\right)$ & $t(h)$ & Yield of 14a (\%) & $\begin{array}{l}\text { e.r. }^{[\mathrm{a}]} \\
(S: R)^{[\mathrm{b}]}\end{array}$ \\
\hline 1 & $(-)-(S)-2 a$ & $\mathrm{AgSbF}_{6}$ & 25 & 30 & 16 & $45: 55$ \\
\hline 2 & $(+)-(R)-2 \mathrm{a}$ & $\mathrm{AgSbF}_{6}$ & 50 & 16 & 52 & $49: 51$ \\
\hline 3 & $(-)-(S)-2 a$ & AgOTf & 50 & 16 & 28 & $51: 49$ \\
\hline 4 & $(+)-(R)-2 \mathrm{a}$ & $\mathrm{AgNTf}_{2}$ & 50 & 26 & 28 & $50: 50$ \\
\hline 5 & $(-)-(S)-2 a$ & AgOTs & 25 & 5 & quant. & $70: 30$ \\
\hline 6 & $(-)-(S)-2 a$ & AgOTs & -20 & 19 & - & - \\
\hline 7 & $(-)-(S)-2 \mathbf{a}$ & AgOTs & 0 & 5 & - & - \\
\hline 8 & $(+)-(R)-2 \mathrm{a}$ & AgOTs & 10 & 7 & 34 & $41: 59$ \\
\hline 9 & $2 \mathbf{j}$ & AgOTs & 25 & 2 & quant. & $50: 50$ \\
\hline 10 & $2 k$ & AgOTs & 25 & 2 & quant. & $51: 49$ \\
\hline 11 & $(+)-2 c$ & AgOTs & 25 & 2 & quant. & $52: 48$ \\
\hline 12 & $(+)-(R)-2 d$ & AgOTs & 25 & 3.5 & quant. & $27: 73$ \\
\hline 13 & $(-)-(R)-2 \mathrm{e}$ & AgOTs & 25 & 2.5 & quant. & $12: 88$ \\
\hline 14 & $(-)-(R)-2 \mathrm{e}$ & AgOTs & -20 & $5 \mathrm{j}$ & quant. & $24: 76$ \\
\hline 15 & $(-)-(R)-2 \mathrm{e}$ & AgOTs & 50 & 1.5 & quant. & $13: 87$ \\
\hline 16 & $(-)-(R)-2 \mathbf{f}$ & AgOTs & 25 & 1.5 & quant. & $8: 92$ \\
\hline 17 & $(R)-2 \mathrm{~g}$ & AgOTs & 25 & 1.5 & quant. & $27: 73$ \\
\hline 18 & $(-)-2 \mathbf{i}$ & AgOTs & 25 & 22 & quant. & $57: 43$ \\
\hline Entry & {$[\mathrm{Au}]$} & {$[\mathrm{Ag}]$} & $\mathrm{T}\left({ }^{\circ} \mathrm{C}\right)$ & $t(h)$ & Yield of 14b (\%) & e.r. ${ }^{[a]}$ \\
\hline $19^{[c]}$ & $(-)-(S)-\mathbf{2 a}$ & $\mathrm{AgSbF}_{6}$ & 25 & 16 & $81 \%$ & $49: 51$ \\
\hline 20 & $(+)-(R)-2 a$ & AgOTs & 25 & 16 & quant. & $60: 40$ \\
\hline 21 & $(+)-(R)-2 d$ & AgOTs & 25 & 1.5 & quant. & $58: 42$ \\
\hline 22 & $(-)-(R)-2 \mathrm{e}$ & AgOTs & 25 & 1.5 & quant. & $74: 26$ \\
\hline 23 & $(+)-(S)-2 f$ & AgOTs & 25 & 1.5 & quant. & $23: 77$ \\
\hline
\end{tabular}

[a] Enantiomeric ratios were determined by chiral HPLC. [b] The configurations were assigned by comparison with literature. ${ }^{[55]}[\mathrm{c}]$ The reaction was run in DCM

Interestingly, with AgOTs at $25^{\circ} \mathrm{C},{ }^{[54]}$ tetrahydrofuran 14a was obtained quantitatively with a promising enantiomeric ratio of 70:30 (entry 5). The absolute configuration of the (S)-major enantiomer was assigned by comparison with previous chiral HPLC data and optical rotation. ${ }^{[55]}$ From a second set of 
experiments with AgOTs, we showed that the reaction does not work at temperatures below $10^{\circ} \mathrm{C}$ and that no enantioselectivity was observed (entries 6-8). From all these experiments, we converged to catalytic reactions at $25^{\circ} \mathrm{C}$ with AgOTs as chloride scavenger as in entry 5 . Screening of the gold complexes brought intriguing findings. We confirmed that for complexes $\mathbf{2 k}$, $2 \mathbf{j}$ and $\mathbf{2 c}$ that do not bear a phosphine oxide moiety, the yields were excellent but quasi-racemic mixtures were obtained (entries 9-11). In contrast, for complex $(+)-(R)-2 \mathbf{d}$ bearing a phosphine oxide moiety, enantioselectivity was restored (e.r. = 27:73, entry 12). This slight improvement compared to (-)-(S)-2a could be ascribed to the larger steric hindrance in vicinity of the gold(I) center brought by the 3,5-dimethylphenyl group on the vinyl carbon. The introduction of 3,5-dimethylphenyl groups on the phosphorus atom as for $(-)-(R)-2 \mathrm{e}$ significantly increased the enantiomeric ratio to $12: 88$ (entry 13 ). As previously shown, the decrease or increase in temperature did not improve the enantioselectivities (entries 14 and 15). Gratifyingly, combining both previous steric constrains by using $(-)-(R)-2 f$ yielded the best e.r. value of $8: 92$ (entry 16). This also corresponds to the best e.r. obtained on $14 \mathrm{a}$ with a carbene gold complex. ${ }^{[66],[17]}$ Using gold(I) complex $(R)$-2g bearing two 3,5-di-tert-butylphenyl groups on the phosphorus atom led however to a lower enantioselectivity (entry 17), suggesting that the steric hindrance around the phosphorus atom does not seem to be the sole factor to influence the enantioinduction. Finally, substitution of the phosphine oxide moiety by a phosphonate $((-)-2 \mathbf{i})$ moiety proved to be highly detrimental to the enantioselectivity (entry 18) giving a e.r. of $57: 43$. Allenol $13 \mathrm{~b}$ gave similar results with each catalyst 2 , the highest enantioselectivity being recorded with $(+)-(S)-2 f$ (entry 23$)$.

The asymmetric intramolecular hydroamination of sulfonamide 15 was next examined. As shown in Table 3, pyrrolidine derivative 16 was obtained in moderate to good yields in $24 \mathrm{~h}$ hours at $50^{\circ} \mathrm{C}$ (Table 2, entries 1-6). The enantiomeric ratios followed the same trend as described for $\gamma$ allenols 13 with the same catalysts. As for $13 b$, the use of precatalysts $(-)-(R)-2 \mathbf{e}$ and $(-)-(R)-2 f$ did not make real difference in terms of enantioselectivity (entries 3 and 4 ).

Table 3. Intramolecular hydroamination.

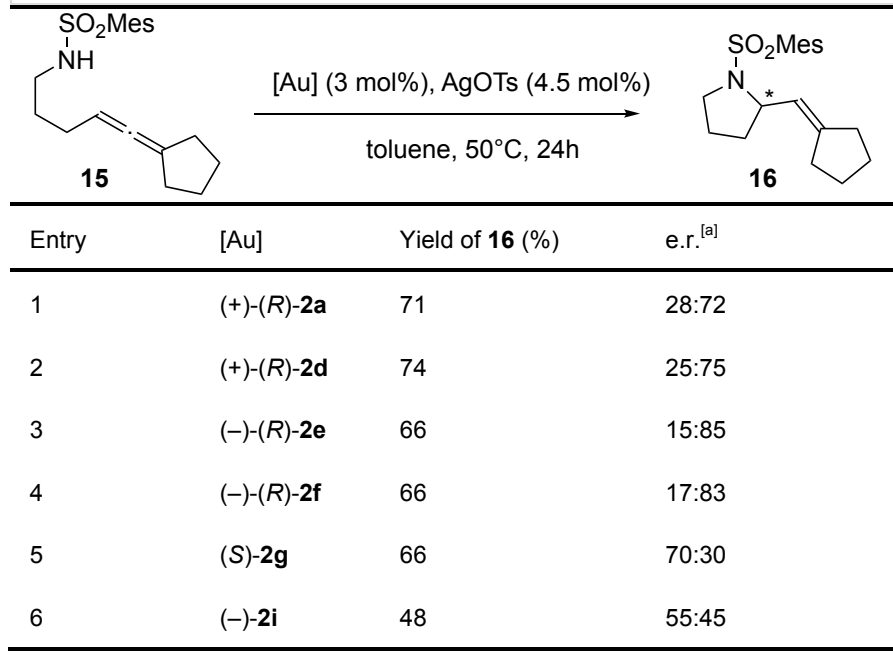

[a] Enantiomeric ratios were determined by chiral HPLC.
Mechanistic aspects. As discussed above, analysis of the XRD structures of most of the neutral chlorinated gold complexes 2 revealed that the privileged conformation is the one where the phosphine oxide moiety is directly pointing towards the $\mathrm{N}$-containing heterocyclic ring (Scheme 1). However, the gold catalysts are effective under their cationic form after abstraction of the chloride ligand. We attempted to crystallize the cationic form of the gold complex $( \pm)-2 \mathbf{a}$ (as a racemic mixture) after anion metathesis using a stoichiometric amount of silver triflimidate.$^{[57]}$ The expected cationic complex $( \pm)-\mathbf{1 7}$ was formed and its XRD structure ${ }^{[58]}$ revealed a dimeric complex with a AuAu distance of $3.0255(4) \AA$, which is characteristic of an aurophilic interaction (Scheme 5). ${ }^{[59]}$ An intermolecular interaction between the phosphine oxide group of one monomer and the gold cationic center of the other one was observed, featuring a distance of 2.091(1) $\AA$ between the $A u$ and $O$ atoms. Thus, this XRD structure confirmed that the pending arm bearing the phosphine oxide group could change its conformation to set the coordination to a cationic gold center.

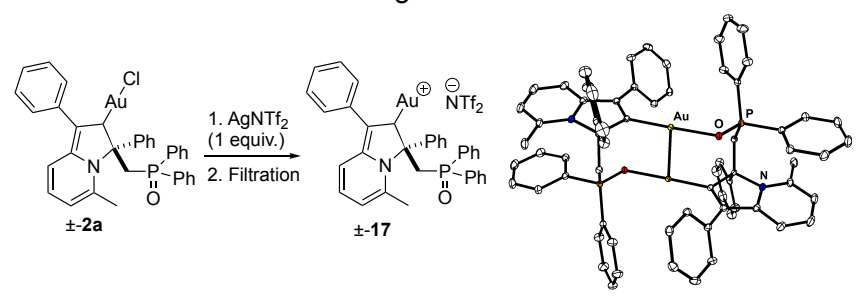

Scheme 5. Synthesis of the cationic catalyst \pm-17 and XRD structure

DFT calculations were also performed to get insight into the mechanism of the cyclisation of a $\gamma$-allenol in order to figure out the crucial role of the phosphine oxide moiety and of the tosylate anion in the cycloisomerization process. Indeed, it appeared that the enantioselective induction was rather effective only in the case where a phosphine oxide was present on the carbene ligand in combination with a tosylate as counterion pointing out a possible participation of these two polar functional groups (see Table 2).

Although an inner-sphere mechanism was initially proposed by Telles in 1998 to describe the gold(I)-catalyzed addition of methanol onto alkynes, ${ }^{[60]}$ the outer-sphere mechanism for the addition of an $\mathrm{O}$ - or $\mathrm{N}$-nucleophile to a gold-coordinated $\mathrm{C}-\mathrm{C}$ multiple bond complex has received much more experimental and theoretical supports. ${ }^{[61]}$ Nevertheless, gold complexes with ligands bearing a judiciously positioned pendant donor function, such as a phosphine oxide ${ }^{[62]}$ or an amine ${ }^{[63]}$ may favour a synaddition through an inner-sphere mechanism. The polar function might also play an active role in the proton transfer steps thanks to its hydrogen-bond acceptor capability. ${ }^{[62]}$ Concerning transformations involving allenes, an inner-sphere mechanism supported by calculations has already been put forward for the intramolecular cyclisation of $\gamma$-amino allenes when a bis-gold phosphine complex was used. ${ }^{[64]}$

In the following DFT study, we considered the inner- and outer-sphere mechanisms for the cycloisomerization of a $\gamma$ allenol yielding to a respective syn- and anti-addition of the hydroxy group onto the gold-activated allene. ${ }^{[65]}$ As mentioned earlier, the presence of the tosylate anion is crucial and therefore its involvement has been taken into consideration. Calculations were performed with the complex (R)-2a.OTs. 
Hexa-4,5-dien-1-ol 18 was used as a model to compute the formation of the $(R)$-vinyltetrahydrofuran product (Figure 3a). As non-polar solvents gave the best results in terms of reactivity and enantioselectivity, it can be assumed that the tosylate anion stays rather close to the gold complex during the whole substrate transformation. Thereby, we considered two starting gold-allene $\eta^{2}$ complexes $\mathbf{I}$ and I' with the tosylate anion interacting either with the metal or with the heterocyclic ring, respectively. In the latter complex l', which is slightly less stable than I by $1.5 \mathrm{kcal}^{\mathrm{mol}}{ }^{-1}$, the electron-rich oxygen of the phosphine oxide is pointing towards the electrophilic metal ( $d$ Au-O = $3.62 \AA$ ) and therefore is located in a suitable position to adopt an appropriate conformation for interactions with the coordinated substrate. A transition state for the inner-sphere mechanism involving unambiguous hydrogen bonding between the phosphine oxide and the hydroxyl group could be computed (blue pathway, Figure $3 a$ ). The optimised structure (S)-TS SYN $_{\text {' }}$ displays an activation barrier of $14.0 \mathrm{kcal}^{\mathrm{mol}}{ }^{-1}$ as a consequence of a beneficial template effect. The nucleophilicity of the hydroxyl group is enhanced by the proximity of the hydrogen-bond acceptor which also accounts for the lower energy barrier observed. The cyclization is endergonic by 9.8 kcal.mol ${ }^{-1}$ from I' and lead to the intermediate $(\boldsymbol{R})$-II' where the protonated tetrahydrofuran is intramolecularly stabilised by the phosphine oxide. Reversibility in the cyclization of $\gamma$-allenols due to ring constraints has already been evidenced experimentally by the groups of Gagné and Widenhoefer ${ }^{[66]}$ The next elementary step to form the desired product is the protodeauration. This step usually requires the assistance of an exogenous molecule playing the role of a proton shuttle. ${ }^{[61 b],[67]}$ Once again, the phosphine oxide group is ideally placed to act this way and operates similarly to a molecular crane by first picking up the proton to deliver it to the reactive C-Au bond. This promotes the protodeauration and furnishes the gold(I)complexed product $(\boldsymbol{R})$-III'.

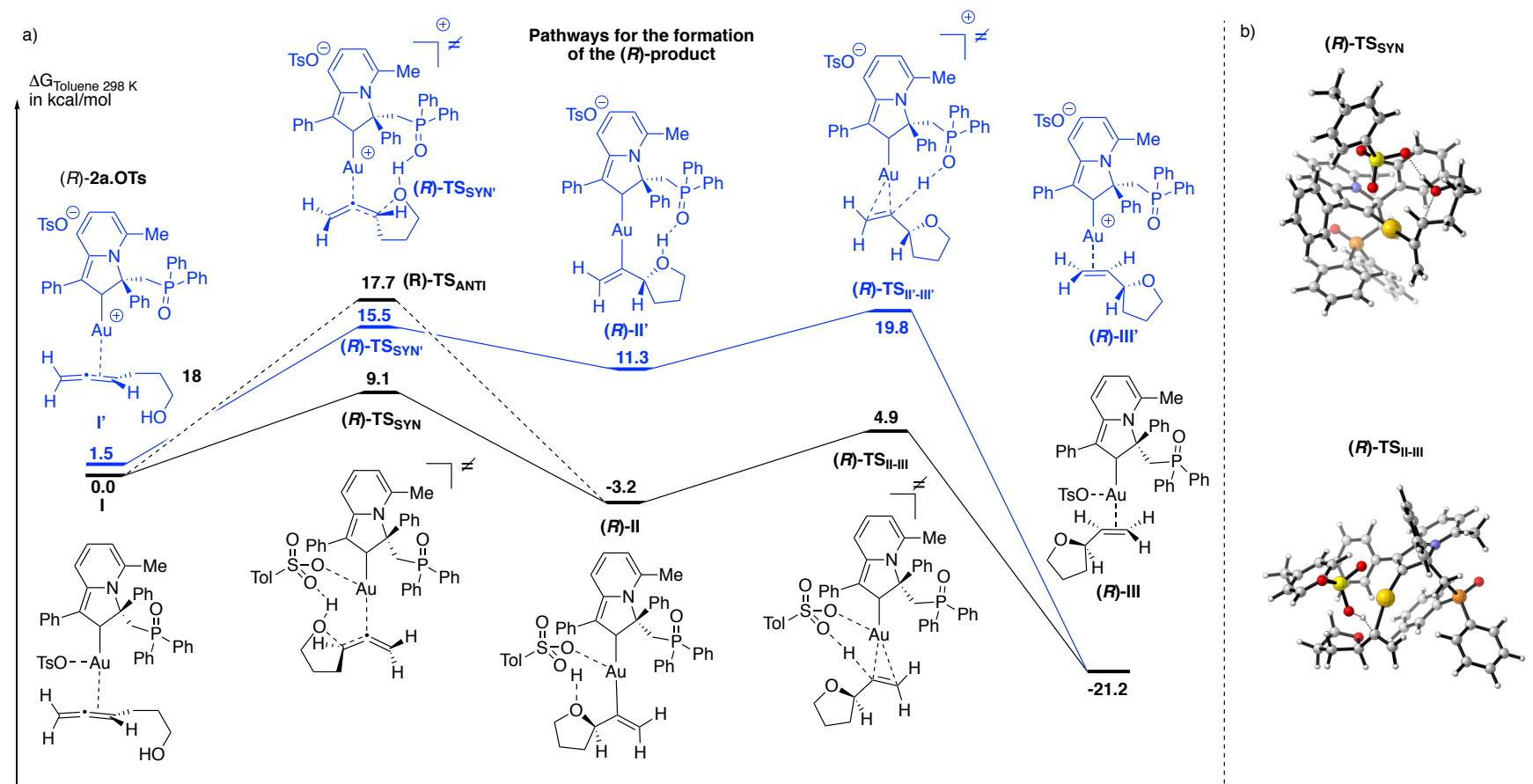

Figure 3. a) Gibbs energy profile for the enantioselective cycloisomerization of $\gamma$-allenol 18 in the presence of $(R)$-2a.OTs at the M06/def2-QZVP(Au)-6$311+G(2 d, p) / / B 3 L Y P-D 3 / S D D(A u)-6-31 G(d, p)$ level of theory (CPCM solvent=toluene). $(R)-T_{A N T I}$ is obtained from an isoenergetic isomer of I with the metal complexed to the other face of the double bond. b) Visualization of the transition states for the cylization and protodeauration steps.

The transition state $(R)-\mathrm{TS}_{\mathrm{II}}-\mathrm{II}$ ' is located $18.3 \mathrm{kcal}^{\mathrm{m}} \mathrm{mol}^{-1}$ above the starting intermediate l'. The overall cycloisomerization process is highly exergonic with an associated energy gain of about $20 \mathrm{kcal}^{\mathrm{mol}}{ }^{-1}$ that totally drives the reaction despite the first endergonic step. In such a case, the tosylate does not play an active role in the transformation. This pathway is very similar to the one calculated with the cationic complex of $(R)-2 \mathrm{a}$ (not taking the anion into consideration, see $\mathrm{SI}$ ). In such a case, the rate determining step of the sequence is the protodeauration. Even though the stereogenic center is installed during the cyclisation, this internal addition is reversible and the small energy barrier to go backwards (about $4 \mathrm{kcal}^{\mathrm{mol}}{ }^{-1}$ ) implies a fast equilibrium. Therefore, the mechanism would follow a
Curtin-Hammett scenario in which the final protodeauration step is the actual stereochemically determining event. ${ }^{[69]}$

However, the tosylate anion is not a weakly coordinating anion and therefore can be involved in the cyclization and the protodeauration steps (black pathway, Figure 3a). Indeed, the activation barrier to reach $(R)$-TS $\mathbf{S}_{\mathbf{S Y N}}$ from the starting intermediate $\mathbf{I}$ is only $9.1 \mathrm{kcal}^{\mathrm{mol}} \mathbf{l}^{-1}$. The tosylate, which is coordinated to the gold center, stabilizes the cyclization transition state through hydrogen bonding. The resulting vinylgold intermediate $(\boldsymbol{R})$-II is more stable than $(\boldsymbol{R})$-II' by 14.5 $\mathrm{kcal} . \mathrm{mol}^{-1}$ and the cyclization becomes exergonic. The antiaddition without the assistance of the tosylate anion was also computed with a corresponding transition state $(R)-\mathrm{TS}_{\mathrm{ANTI}}$ lying 
about $9 \mathrm{kcal} . \mathrm{mol}^{-1}$ above the syn-addition. The protodeauration step can also be assisted by the tosylate. The transient $p$ toluenesulfonic acid delivers the proton to the $\mathrm{C}-\mathrm{Au}$ bond through $(R)-\mathrm{TS}_{\text {II-III }}$ with an activation barrier of only $8.1 \mathrm{kcal}^{\mathrm{mol}}{ }^{-1}$ from $(\boldsymbol{R})$-II to lead to the final intermediate $(\boldsymbol{R})$-III. Interestingly, in this pathway with the tosylate coordinated to the gold center, the oxygen of the phosphine oxide prefers to point towards the electron-deficient $\mathrm{N}$-containing heterocyclic ring (d O-N $=2.96 \AA$ in structure I). The favored interaction brings some rigidity to the system and forces the phosphine oxide moiety to display its two aromatic substituents nearby the chiral active catalytic site, which rationalizes the influence of the aromatic rings substitution on the enantioinduction. In this pathway, the cyclization is the stereochemically-determining step. Gratifyingly, the formation of the $(S)$-vinyltetrahydrofuran product could be computed as well and the transition state corresponding to the cyclization step is higher than the one calculated for the $(R)$-product by 1.3 $\mathrm{kcal} . \mathrm{mol}^{-1}$ (see SI). Although this DFT study has been carried out with a simpler model, the results are consistent with the finding that allenol $13 \mathrm{a}$ is converted into $(R)-14 \mathrm{a}$ using $(R)-2 \mathrm{a}$ and analogues as precatalysts.

\section{Conclusion}

In summary, we have designed a new family of gold(I) complexes based on indolizine-ylidene (Indolizy) ligands. These complexes are readily available from the gold(I)-promoted cyclization of allenylpyridines. The evaluation of the electronic features of the Indolizy ligand has shown highly $\sigma$-donor and $\pi$ acceptor properties. For that we have relied on a diagnostic reaction and on various NMR analyses. Among others, we used the Huynh's HEP method which had never been used for any carbene other than NHCs. All findings were supported by DFT calculations. Chiral gold(I) complexes could be separated by chiral HPLC and evaluated in asymmetric catalysis. Chiral bifunctional ligands presenting a pending phosphine oxide moiety on the stereogenic center afforded highly efficient and enantioselective cycloisomerizations of $\gamma$-functionalized allene derivatives. Increasing the steric demand on the phosphine oxides promoted the best enantiomeric ratios. DFT calculations suggested several possible scenarios highlighting the crucial roles of the phosphine oxide moiety and the tosylate counterion.

\section{Acknowledgements}

The authors thank Sorbonne Universite ( $\mathrm{PhD}$ grant to TM), the Franco Thai Scholarship Program administered by CAMPUS FRANCE, IUF and CNRS for financial support. We are also grateful to Lise-Marie Chamoreau (IPCM) for the XRD data and Manon Louis for the studies related to $\mathbf{2 h}$.

\section{Conflic of interest}

The authors declare no conflict of interest.
Keywords: carbene $\cdot$ gold $\cdot$ phosphine oxide $\cdot$ asymmetric catalysis • DFT

[1] (a) Homogenous Gold Catalysis, V. Michelet, F. D. Toste, Eds., Imperial College Press: London, 2014; (b) Modern Gold Catalysis Synthesis, A. S. K. Hashmi, F. D.Toste, Eds.; Wiley, 2012.

[2] For recent reviews, see: a) L. Fensterbank, M. Malacria, Acc. Chem.Res. 2014, 47, 953-965; b) R. Dorel, A. M. Echavarren, Chem. Rev. 2015, 115, 9028-9072; c) D. Pflästerer, A. S. K. Hashmi, Chem. Soc. Rev. 2016, 45, 1331-1367; d) R. Herrera, M. C. Gimeno, Chem. Rev. 2021, DOI: 10.1021/acs.chemrev.0c00930; e) C.C. Chintawar, A. K. Yadav, A. Kumar, S. P. Sancheti, N. T. Patil, Chem. Rev. 2021, DOI: 10.1021/acs.chemrev.0c00903; f) D. Campeau, D. F. Leon Rayo, A. Mansour, K. Muratov, F. Gagosz, Chem. Rev. 2020, DOI: 10.1021/acs.chemrev.0c00788; g) M. Mato, A. Franchina, C. GarciaMorales, A. M. Echevarren, Chem. Rev. 2020, DOI: 10.1021/acs.chemrev.0c00697; h) R. L. Reyes, T. Iwai, M. Sawamura, Chem. Rev. 2020, DOI: 10.1021/acs.chemrev.0c00793.

[3] Z. Lu, G. B. Hammond, B. Xu, Acc. Chem. Res. 2019, 52, 1275-1288.

[4] W. Zi, F. D. Toste, Chem. Soc Rev. 2016, 45, 4567-4589.

[5] a) W. A. Herrmann, Angew. Chem. Int. Ed., 2002, 41, 1290-1309, Angew. Chem. Int. Ed., 2002, 114, 1342-1363; b) S. Díez-González, N. Marion, S. P. Nolan, Chem. Rev. 2009, 109, 3612-3676; c) F. Glorius N-Heterocyclic Carbenes in Transition Metal Catalysis, Vol. 21 (Ed.: F. Glorius), Springer-Verlag, Berlin/Heidelberg, 2007. d) M. N. Hopkinson, C. Richter, M. Schedler, F. Glorius, Nature 2014, 510, 485-496.

[6] a) H. Jacobsen, A. Correa, A. Poater, C. Costabile, L. Cavallo, Coord. Chem. Rev. 2009, 253, 687-703; b) D. J. Nelson, S. P. Nolan, Chem. Soc. Rev. 2013, 42, 6723-6753; b) T. Dröge, F. Glorius, Angew. Chem. 2010,122, 7094-7107; Angew. Chem. Int. Ed. 2010, 49, 6940-6952; c) D. Gatineau, J.-P. Goddard, V. Mansuy, L. Fensterbank, Isr. J. Chem. 2013, 53, 892-900.

[7] V. Lavallo, Y. Canac, C. Präsang, B. Donnadieu, G. Bertrand, Angew. Chem. Int. Ed. 2005, 44, 5705-5709; Angew. Chem. 2005, 117, 58515855; b) M. Soleilhavoup, G. Bertrand, Acc. Chem. Res. 2015, 48, 256266.

[8] M. Melaimi, R. Jazzar, M. Soleihavoup, G. Bertrand, Angew. Chem. Int. Ed. 2017, 56, 10046-10068; Angew. Chem. 2017, 129,10180-10203.

[9] R. Jazzar, M. Soleilhavoup, G. Bertrand, Chem. Rev. 2020, 120, 41414168.

[10] a) V. Lavallo, G. D. Frey, B. Donnadieu, M. Soleilhavoup, G. Bertrand, Angew. Chem. Int. Ed. 2008, 47, 5224-5228; Angew. Chem. 2008, 120, 5302-5306; b) R. Kinjo, B. Donnadieu, G. Bertrand, Ang. Chem. Int. Ed. 2011, 50, 5560-5563; Ang. Chem. 2011, 123, 5674-5677.

[11] B. Rao, H. Tang, X. Zeng, L. Liu, M. Melaimi, G. Bertrand, Angew. Chem. Int. Ed. 2015, 54, 14915-14919; Angew. Chem. 2015, 127, 15128-15132.

[12] D. Janssen-Müller, C. Schlepphorst, F. Glorius, Chem. Soc. Rev. 2017, 46, 4845-4854

[13] For review on complexes of coinage metals with chiral NHCs, see: S. Budagumpi, R. S. Keri, G. Achar, K. N. Brinda, Adv. Synth. Catal. 2020, 362, 970-997.

[14] Y. Matsumoto, K. S. Selim, H. Nakanishi, K.-I. Yamada, Y. Yamamoto, K. Tomioka, Tetrahedron Lett. 2010, 51, 404-406.

[15] D. Banerjee, A. K. Buzas, C. Besnard, E. P. Kündig, Organometallics 2012, 31, 8348-8354.

[16] B. W. Gung, M. R. Holmes, C. A. Jones, R. Ruoyu Ma, C. L. Barnes, Tet. Lett. 2016, 57, 3912-3915.

[17] a) For a recent review on chiral NHCs see: M. Michalak, W. Kośnik, Catalysts 2019, 9, 890, doi:10.3390/catal9110890; b) for seminal work on acyclic chiral carbenes, see: S. Handa, L. M. Slaughter, Angew. Chem. Int. Ed. 2012, 51, 2912-2915; Angew. Chem. Int. Ed. 2012, 124 , 2966-2969.

[18] M. Alcarazo, S. J. Roseblade, A. R. Cowley, R. Fernández, J. M. Brown, J. M. Lassaletta, J. Am. Chem. Soc. 2005, 127, 3290-3291.

[19] C. Burstein, C. W. Lehmann, F. Glorius, Tetrahedron 2005, 61, 62076217. 
[20] For robust gold(I) complexes bearing a barbituric heterocycle at the C5 position, see: Y. Tang, I. Benaissa, M. Huynh, L. Vendier, N. Lugan, S Bastin, P. Belmont, V. César, V. Michelet, Angew. Chem. 2019, 131,8061-8065; Angew. Chem. Int. Ed. 2019, 58, 7977-7981.

[21] M. Alcarazo, S. J. Roseblade, A. R. Cowley, R. Fernández, J. M. Brown, J. M. Lassaletta, J. Am. Chem. Soc. 2005, 127, 3290-3291.

[22] J. Francos, F. Grande-Carmona, H. Faustino, J. Iglesias-Sigüenza, E. Díez, I. Alonso, R. Fernández, J. M. Lassaletta, F. López, J. L. Mascareñas, J. Am. Chem. Soc. 2012, 134, 14322-14325.

[23] J.-Q. Zhang, Y. Liu, X.-W. Wang, L. Zhang, Organometallics 2019, 38, 3931-3938.

[24] D. Pichon, M. Soleilhavoup, J. Morvan, G. P. Junor, T. Vives, C. Crévisy, V. Lavallo, J.-M. Campagne, M. Mauduit, R. Jazzar, G. Bertrand, Chem. Sci. 2019, 10, 7807-7811.

[25] For Ru complexes bearing C1-symmetric cyclic CAAC ligands giving high enantioselectivities in asymmetric olefin metathesis, see: $\mathrm{J}$. Morvan, F. Vermersch, Z. Zhang, L. Falivene, T. Vives, V. Dorcet, T. Roisnel, C. Crévisy, L. Cavallo, N. Vanthuyne, G. Bertrand, R. Jazzar, M. Mauduit, J. Am. Chem. Soc. 2020, 142, 19895.

[26] F. Kolundžić, A. Murali, P. Pérez-Gálan, J. O. Bauer, C. Strohmann, K. Kumar, H. Waldmann, Angew. Chem. 2014,126, 8260-8264; Angew. Chem. Int. Ed., 2014, 53, 8122-8126.

[27] F. Schröder, C. Tugny, E. Salanouve, H. Clavier, L. Giordano, D. Moraleda, Y. Gimbert, V. Mouriès-Mansuy, J.-P. Goddard, L. Louis Fensterbank, Organometallics, 2014, 33, 4051-4056.

[28] A. Vanitcha, C. Damelincourt, G. Gontard, N. Vanthuyne, V. MourièsMansuy, L. Fensterbank, Chem. Commun. 2016, 52, 6785-6788.

[29] C. Tugny, N. del Rio, M. Koohgard, N. Vanthuyne, D. Lesage, K. Bijouard, P. Zhang, J. Meijide Suárez, S. Roland, E. Derat, O. BistriAslanoff, M. Sollogoub, L. Fensterbank, V. Mouriès-Mansuy, ACS Catal. 2020, 10, 5964-5972.

[30] For a recent example of bifunctional NHC-AuCl complex, see: O. Seppänen, S. Aikonen, M. Muuronen, C. Alamillo-Ferrer, J. Burès, J. Helaja, Chem. Commun. 2020, 56, 14697-14700.

[31] A. Vanitcha, G. Gontard, N. Vanthuyne, E. Derat, V. Mouriès-Mansuy, L. Fensterbank, Adv. Synth. Catal. 2015, 357, 2213-2218.

[32] For recent similar approaches, see: a) H. K. Wagner, H. Wadepohl, J. Ballmann, Chem. Science 2021,12, 3693-3701; b) S. Arndt, M. M. Hansmann, P. Motloch, M. Rudolph, F. Rominger, A. S. K. Hashmi Chem. Eur. J. 2017, 23, 2542-2537; c) A. S. K. Hashmi, D. Riedel, M Rudolph, F. Rominger, T. Oeser, Chem. Eur. J. 2012, 18, 3827-3830.

[33] CCDC deposition numbers: 2a, 1055996; 2c, 2064282; 2d, 2064283; 2e, 2064284; 2f, 2064285

[34] a) For a review, see: Y. Wang, M. E. Muratore, A. M. Echavarren, Chem. Eur. J. 2015, 21, 7332-7339; b) See also: M. Joost, L. Estevez, S. Mallet-Ladeira, K. Miqueu, A. Amgoune, D. Bourissou, Angew. Chem. Int. Ed. 2014, 53, 14512-14516; Angew. Chem. 2014, 126, 14740-14744

[35] H. K. Maliszewska, D. L. Hughes, M. P. Muñoz, Dalton Trans. 2020, 49, 4034-4038.

[36] CCDC deposition number for(-)-(S)-2a: 2081677.

[37] See supporting information and also ref. 28.

[38] J. K. E. T. Berton, H. Salemi, J.-L. Pirat, D. Virieux, C. V. Stevens, J. Org. Chem. 2017, 82, 12439-12446.

[39] CCDC deposition number for 2k: 2064286.

[40] H. V. Huynh, Chem. Rev. 2018, 118, 9457-9492.

[41] A. A. Tukov, A. T. Normand, M. S. Nechaev, Dalton Trans. 2009, 70157028.

[42] H. Song, H. Kim, E. Lee, Angew. Chem. Int. Ed. 2018, 57, 8603-8607; Angew. Chem. 2018, 130, 8739-8743.

[43] a) D. Munz, Organometallics 2018, 37, 275-289; b) D. M. Andrada, N Holzmann, T. Hamadi, G. Frenking, Beilstein J. Org. Chem. 2015, 11, 2727-2736.

[44] E. A. Carter, W. A. Goddard III, J. Phys. Chem. 1986, 90, 998-1001.

[45] S. Guo, H. Sivaram, D. Dan Yuan, H. V. Huynh, Organometallics 2013, 32, 3685-3696.

[46] Q. Teng, H. V. Huynh, Dalton Trans. 2017, 46, 614-627.

[47] CCDC deposition number for 6: 2064288.
[48] A. Liske, K. Verlinden, H. Buhl, K. Schaper, C. Ganter, Organometallics 2013, 32, 5269-5272.

[49] S. V. C. Vummaleti, D. J. Nelson, A. Poater, A. Gomez-Suarez, D. B. Cordes, A.M. Z. Slawin, S. P. Nolan, L. Cavallo, Chem. Sci. 2015, 6, 1895-1904.

[50] For the reaction of related allenyl pyridines with $\mathrm{I}_{2}$, see: T. Martinez, I. Alahyen, G. Lemière, V. Mouriès-Mansuy, L. Fensterbank Org. Process. Res. Dev. 2020, 24, 817-821.

[51] CCDC deposition number for 6: 2064288.

[52] a) B. Trillo, F. Lopez, S. Montserrat, G. Ujaque, L. Castedo, A. Lledos, J. L. Mascarenas, Chem. Eur. J. 2009, 15, 3336 -3339; b) I. Alonso, B. Trillo, F. Lopez, S. Montserrat, G. Ujaque, L. Castedo, A. Lledos, J. L. Mascarenas, J. Am. Chem. Soc. 2009, 131, 13020-13030; c) P. Mauleon, R. M. Zeldin, A. Z. Gonzalez, F. D. Toste, J. Am. Chem. Soc. 2009, 131, 6348-6348; d) J. Petuskova, H. Bruns, M. Alcarazo, Angew. Chem. Int. Ed. 2011, 50, 3799-3802; Angew. Chem. Int. Ed. 2011, 123, 3883-3886; e) A. H. Christian, Z. L. Niemeyer, M. S. Sigman, F. D. Toste, ACS Catal. 2017, 7, 3973-3978.

[53] It should be noted that thiophosphine complex $\mathbf{2 h}$ is not stable in the catalytic reaction conditions.

[54] Z. Zhang, R. A. Widenhoefer, Angew. Chem. Int. Ed. 2007, 46, 283285; Angew. Chem. 2007, 119, 287-289.

[55] a) Z. Wang, C. Nicolini, C. Hervieu, Y.-F. Wong, G. Zanoni, L. Zhang J. Am. Chem. Soc. 2017, 139, 16064-16067; b) J. L. Arbour, H. S. Rzepa, J. Contreras-García, L. A. Adrio, E. M. Barreiro, K. K. (Mimi) Hii Chem. Eur. J. 2012, 18, 11317-11324.

[56] C. Bartomolé, D. Garcia-Cuadrado, Z. Ramiro, P. Espinet Inorg. Chem. 2010, 49, 9758-9764.

[57] N. Mézailles, L. Ricard, F. Gagosz, Org. Lett. 2005, 7, 4133-4136.

[58] CCDC deposition number for 17, 2064289.

[59] H. Schmidbaur, A. Schier, Chem. Soc. Rev. 2008, 37, 1931-1951.

[60] J. H. Teles, S. Brode, M. Chabanas, Angew. Chem., Int. Ed. 1998, 37, 1415-1418; Angew. Chem. 1998,

[61] a) Z. Zhang, R. A. Widenhoefer, Angew. Chem. 2007, 119, 287-292; Angew. Chem. Int. Ed. 2007, 46, 283 -285; b) R. S. Paton, F. Maseras, Org. Lett. 2009, 11, 2237-2240; c) Z. J. Wang, D. Benitez, E. Tkatchouk, W. A. Goddard III, F. D. Toste, J. Am. Chem. Soc. 2010, 132, 1306413071; d) T. J. Brown, D. Weber, M. R. Gagné, R. A. Widenhoefer, J. Am. Chem. Soc. 2012, 134, 9134-9137; e) R. J. Harris, R. G. Carden, A. N. Duncan, R. A. Widenhoefer, ACS Catal. 2018, 8, 8941-8952.

[62] C. Hahn, L. Cruz, A. Villalobos, L. Garzaa, S. Adeosun, Dalton Trans. 2014, 43, 16300-16309.

[63] K. D. Hesp, M. Stradiotto, J. Am. Chem. Soc. 2010, 132, 18026-18029.

[64] J. H. Kim, S.-W. Park, S. R. Park, S. Lee, E. J. Kang, Chem. Asian J. 2011, 6, 1982-1986.

[65] a) E. Soriano, I. Fernández, Chem. Soc. Rev., 2014, 43, 3041-3105; b) M. Malacria, L.Fensterbank, V. Gandon, Top. Curr. Chem. 2011, 302, 157-182.

[66] T. J. Brown, D. Weber, M. R. Gagné, R. A. Widenhoefer, J. Am. Chem. Soc. 2012, 134, 9134-9137.

[67] a) C. M. Krauter, A. S. K. Hashmi, M. Pernpointner, ChemCatChem 2010, 2, 1226-1230. b) Ciancaleoni, G.; Belpassi, L.; Zuccaccia, D.; Tarantelli, F.; Belanzoni, P. ACS Catal. 2015, 5, 803-814.

[68] W. Wang, G. B. Hammond, B. Xu, J. Am. Chem. Soc. 2012, 134, 56975705 .

[69] R. E. M. Brooner, T. J. Brown, M. A. Chee, R. A. Widenhoefer, Organometallics 2016, 35, 2014-2021. 


\section{Entry for the Table of Contents}

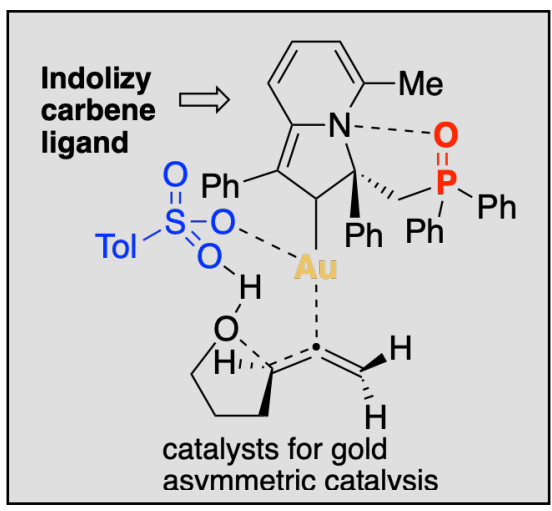

$\mathrm{Au}(\mathrm{I})$ complexes coordinated to the Indolizy ligand, a new carbene ligand that results from the gold-promoted cyclization of a pyridylallene were investigated. The electronic properties of the Indolizy ligand were gauged thanks to physical analyses and DFT calculations. The introduction of stereogenic center in $\alpha$-position to the carbene center coupled to the introduction of a pending phosphine oxide group affords highly efficient and enantioselective $\mathrm{Au}(\mathrm{I})$ catalysts.

Institute and/or researcher Twitter usernames: @IPCM_Sorbonne 